\title{
Trauma Centrality and PTSD Symptom Severity in Adult Survivors of Childhood Sexual Abuse
}

\section{Citation}

Robinaugh, Donald John, and Richard J. McNally. 2011. Trauma centrality and PTSD symptom severity in adult survivors of childhood sexual abuse. Journal of Traumatic Stress 24(4): 483-486.

\section{Published Version}

doi:10.1002/jts.20656

\section{Permanent link}

http://nrs.harvard.edu/urn-3:HUL.InstRepos:8916506

\section{Terms of Use}

This article was downloaded from Harvard University's DASH repository, and is made available under the terms and conditions applicable to Open Access Policy Articles, as set forth at http:// nrs.harvard.edu/urn-3:HUL.InstRepos:dash.current.terms-of-use\#OAP

\section{Share Your Story}

The Harvard community has made this article openly available.

Please share how this access benefits you. Submit a story.

Accessibility 
Overall Word Count (text, references, tables, and figures): 2,484

Manuscript Word Count: 1,407

Footnote Word Count: 52

References Word Count: 450

Tables Word Count: 572

Abstract Word Count: 100

Tables: 4

Figures: 0

References: 26

Trauma Centrality and PTSD Symptom Severity in Adult Survivors of Childhood Sexual Abuse Donald J. Robinaugh and Richard J. McNally Department of Psychology, Harvard University

Author Note

Donald J. Robinaugh and Richard J. McNally, Department of Psychology, Harvard University.

This research was supported by a grant from the Milton Fund.

Correspondence concerning this article should be addressed to Donald J. Robinaugh, Department of Psychology, Harvard University, 33 Kirkland Street, Cambridge, MA 02138. Email: robinaug@fas.harvard.edu

Abstract 
To test whether regarding a trauma as central to one's identity leads to greater Posttraumatic Stress Disorder (PTSD) symptom severity, we administered the Centrality of Events Scale (CES) to 102 women reporting a history of childhood sexual abuse. CES scores correlated with PTSD symptom severity, depression severity, and self-esteem. Principal component analysis of the CES uncovered three factors reflecting 1) the centrality and integration of the trauma, 2) whether one regards the trauma as a turning point in one's life story, and 3) whether the event anchors for expectations about the future. Each factor was associated with PTSD symptom severity. 
Trauma Centrality and PTSD Symptom Severity in Adult Survivors of Childhood Sexual Abuse Accessible, vivid, and affectively intense memories structure our autobiographical narratives, inform our sense of self, and act as reference points for our expectations and attributions in everyday life (Berntsen \& Rubin, 2007). Increasingly, researchers are using Berntsen and Rubin's (2006) Centrality of Events Scale (CES) to examine the impact of regarding a trauma as a central aspect of one's identity. CES scores for traumatic or highly aversive events are positively associated with PTSD symptom severity among undergraduates (e.g., Berntsen \& Rubin, 2006, 2007; Robinaugh \& McNally, 2010). and among combat veterans (Brown, Antonius, Kramer, Root, \& Hirst, 2010).

Although CES items load onto a single centrality-of-event factor (Berntsen \& Rubin, 2006), Berntsen and Rubin developed the scale to assess three presumably distinct constructs. The first denotes the extent to which one regards an event as a turning point in one's life story. The second denotes the extent to which the event is central to one's identity. Although these constructs have their theoretical roots in the autobiographical memory literature (e.g., Pillemer, 1998), they are also relevant to several theories of PTSD. In particular, cognitive theorists have highlighted the etiological importance of negative trauma-related self-appraisals (Brewin \& Holmes, 2003). These self-appraisals (e.g., "I have permanently changed for the worse" Foa, Ehlers, Clark, Tolin, \& Orsillo, 1999) resemble items on the CES (e.g., "This event permanently changed my life."). Accordingly, a positive association between these constructs and PTSD severity is consistent with both cognitive (e.g., Ehlers \& Clark, 2000) and mnemonic (Rubin, Berntsen, \& Bohni, 2008) models of PTSD. The third construct concerns the extent to which the event acts as a reference point structuring the organization of autobiographical memory and informing attributions and expectations. Several PTSD models (e.g., Ehlers \& Clark, 2000; 
Herman, 1992) hold that a failure to integrate a traumatic event with other autobiographical memories contributes to the development of PTSD. In contrast, others have argued that greater integration of the trauma heightens its accessibility, promotes voluntary and involuntary retrieval, and worsens PTSD (Berntsen \& Rubin, 2007). These researchers cite the positive association between CES scores and PTSD as evidence that greater integration leads to greater PTSD (Berntsen \& Rubin, 2007). However, items addressing the "identity" and "turning point" constructs may drive this positive association rather than those addressing the integration of the trauma with other autobiographical memories. Accordingly, there is a need to examine the association between each CES construct and posttraumatic distress.

In this study, we tested whether greater CES scores would be associated with greater psychological distress and poorer self-esteem in women reporting a history of childhood sexual abuse (CSA). Furthermore, we hypothesized that CES scores would remain associated with PTSD symptom severity after we controlled for depression severity, self-esteem, and two risk factors for PTSD: intelligence (McNally \& Shin, 1995) and dissociation (Ozer, Best, Lipsey, \& Weiss, 2003). Finally, we conducted a principal component analysis (PCA) to uncover the three CES constructs, and to test whether there is a positive association between each of them and psychological distress.

\section{Method}

\section{Participants}

The subjects were women who reported a history of CSA $(n=102)$ who responded to our advertisement for a study on risk and resilience. Fifty-two percent were Caucasian, and their mean age was 42.5 years $(S D=12.1)$. A phone screen confirmed that each woman had experienced at least one episode of sexual abuse prior to the age of 17 involving physical contact 
with (e.g., fondling, oral-genital contact,) a perpetrator who was at least five years older than the victim was. The Institutional Review Board of Harvard University approved the protocol and consent form. Participants provided written informed consent.

\section{Measures}

Centrality of Events Scale. The CES (Berntsen \& Rubin, 2006) is a 20-item questionnaire with items rated on a scale of 1 (Strongly Disagree) to 5 (Strongly Agree). We asked participants to rate items in reference to the CSA. Following Berntsen and Rubin, we calculated the CES score as the mean of all items.

Psychological distress. We administered the Posttraumatic Checklist - Civilian Version (PCL; Weathers, Litz, Herman, Huska, \& Keane, 1993) and Beck Depression Inventory-II (Beck, Steer, \& Brown, 1996) to assess symptom severity of PTSD and depression, respectively. For the PCL, participants rated each item in reference to the CSA. In addition, we administered the Rosenberg Self-Esteem Scale (RSS; Rosenberg, 1965, pp. 305-307) to assess self-esteem.

Risk factors for PTSD. To assess intelligence, we administered Shipley Institute for Living Scale (Zachary, 1991) and converted each subject's score into its estimated WAIS-R equivalent. We administered the Dissociative Experiences Scale (DES; Bernstein \& Putnam, 1986) to assess dissociation.

\section{Results}

We calculated product-moment correlations among the CES, PCL, BDI, RSS, and DES scores (Table 1). CES scores were positively associated with each variable. We next conducted a single-step multiple linear regression analysis to determine if CES scores were associated with PTSD symptom severity after we controlled statistically for age, intelligence, and BDI, RSS, and DES scores (see Table 2). CES continued to predict PTSD symptom severity $(\beta=.43, p<.001)$. 
To examine the factors underlying the CES, we performed an iterated principal component analysis (PCA) with varimax rotation ${ }^{1}$. The PCA produced 4 factors with eigenvalues exceeding the Kaiser criterion $(9.88,1.54,1.16$, and 1.04; Kaiser, 1960). The inflexion point of the Scree plot (Cattell, 1966) occurred at the $3^{\text {rd }}$ eigenvalue. Accordingly, we evaluated both a three-factor and four-factor solution. Relative to the four-factor solution, the three-factor solution produced a more clearly interpretable pattern of findings. In the three-factor rotated solution (see Table 3), Factors 1, 2, and 3 accounted for $23.49 \%, 19.96 \%$, and $19.42 \%$ of the variance in CES items, respectively. Finally, we calculated the product-moment correlations between the three factor scores and RSS, PCL, and BDI scores (Table 1). Each factor was associated with PCL scores.

\section{Discussion}

Researchers have reported a positive association between CES scores and PTSD symptom severity in undergraduate students and combat veterans (Berntsen \& Rubin, 2006; Brown et al., 2010). In this study, we extended these findings to women reporting a history of childhood sexual abuse. CES scores were positively associated with PTSD and depression symptom severity and negatively associated with self-esteem. The association between CES scores and PTSD remained significant after we controlled statistically for depression severity, self-esteem, age, intelligence, and dissociation.

PCA revealed that the CES contains three factors that closely, though not precisely, reflect the constructs that Berntsen and Rubin (2006) designed it to address. Factor 1 contained items tapping both centrality to identity and the integration with other memories. This factor was positively associated with PTSD symptom severity, implying that greater integration contributes to greater severity of PTSD. Factor 2 contained items addressing whether one considers the 
event as a turning point in one's life (i.e., having been changed by the event); it, too, was positively associated with PTSD severity. Factor 3 predominately contained items addressing the extent to which victims view the future through the lens of CSA. Interestingly, this factor exhibited a notably greater association with PTSD symptom severity than did the "Centrality" and "Turning Point" factors, suggesting that holding a traumatic event as central to one's future may be more psychologically toxic than appraising the event as a key to one's current identity.

Our study has limitations. The data are cross-sectional, precluding determination of causality. In addition, although our sample size exceeded the minimum recommended subject-toitem ratio (Gorusch, 1983, p. 32), it was modest for exploratory factor analysis (Comfrey \& Lee, 1992). Furthermore, several items loaded highly on multiple factors. Given previous findings that CES items load onto a single factor (Berntsen \& Rubin, 2006), these limitations suggest some caution may be warranted in interpreting our PCA results .

The PTSD field lacks a consensus definition of what it means to "integrate" a trauma into one's life story. We interpreted integration as the extent to which victims perceive connections between the trauma and other autobiographical memories. By this definition, greater integration was associated with greater PTSD symptom severity. The implications of our results for alternative conceptualizations of integration are unclear.

Individuals who appraise a traumatic event as a turning point in their life story, a central part of their identity, and a reference point for generating expectations about the future exhibit greater distress. Our results suggest that individuals who appraise a traumatic event as a reference point for their future may be especially at risk for PTSD. 


\section{References}

Beck, A. T., Steer, R. A., \& Brown, G. K. (1996). Manual for the Beck Depression Inventory-II. San Antonio, TX: Psychological Corporation.

Berntsen, D., \& Rubin, D. C. (2006). The centrality of event scale: A measure of integrating a trauma into one's identity and its relation to post-traumatic stress disorder symptoms. Behaviour Research and Therapy, 44, 219-231.

Berntsen, D., \& Rubin, D. C. (2007). When a trauma becomes a key to identity: Enhanced integration of trauma memories predicts posttraumatic stress disorder symptoms. Applied Cognitive Psychology, 21, 417-431.

Brewin, C. R., \& Holmes, E. A. (2003). Psychological theories of posttraumatic stress disorder. Clinical Psychology Review, 23, 339-376.

Brown, A. D., Antonius, D., Kramer, M., Root, J. C., \& Hirst, W. (2010). Trauma centrality and PTSD in veterans returning from Iraq and Afghanistan. Journal of Traumatic Stress, 23, 496-499.

Cattell, R. B. (1966). The scree test for the number of factors. Multivariate Behavioral Research, $1,245-276$.

Comfrey, A. L., \& Lee, H. B. (1992). A first course in factor analysis. Hillsdale, NJ: Erlbaum.

Ehlers, A., \& Clark, D. M. (2000). A cognitive model of posttraumatic stress disorder. Behaviour Research and Therapy, 38, 319-345.

Foa, E. B., Ehlers, A., Clark, D. M., Tolin, D. F., \& Orsillo, S. M. (1999). The Posttraumatic Cognitions Inventory (PTCI): Development and validation. Psychological Assessment, $11,303-314$.

Gorusch, R. L. (1983). Factor Analysis (2nd ed.). Hillsdale, NJ: Erlbaum. 
Herman, J. L. (1992). Trauma and recovery. New York: Basic Books.

Kaiser, H. F. (1960). The application of electronic computers to factor analysis. Educational and Psychological Measurement, 10, 141-151.

McNally, R. J., \& Shin, L. M. (1995). Association of intelligence with severity of posttraumatic stress disorder symptoms in Vietnam Combat veterans. American Journal of Psychiatry, $152,936-938$.

Ozer, E. J., Best, S. R., Lipsey, T. L., \& Weiss, D. S. (2003). Predictors of posttraumatic stress disorder and symptoms in adults: a meta-analysis. Psychological Bulletin, 129, 52-73.

Pillemer, D. B. (1998). Momentous events, vivid memories. Momentous events, vivid memories. Cambridge, MA: Harvard University Press.

Robinaugh, D. J., \& McNally, R. J. (2010). Autobiographical memory for shame or guilt provoking events: Association with psychological symptoms. Behaviour Research and Therapy, 48, 646-652.

Rosenberg, M. (1965). Society and the adolescent self-image. Princeton, NJ: Princeton University Press.

Rubin, D. C., Berntsen, D., \& Bohni, M. K. (2008). A memory-based model of posttraumatic stress disorder: Evaluating basic assumptions underlying the PTSD diagnosis. Psychological Review, 115, 985-1011.

Weathers, F. W., Litz, B., Herman, D., Huska, J., \& Keane, T. (1993). The PTSD Checklist (PCL): Reliability, Validity, and Diagnostic Utility Annual Convention of the International Society for Traumatic Stress Studies. San Antonio, TX.

Zachary, R. A. (1991). Shipley Institute of Living Scale (Revised). Los Angeles: Western Psychological Services. 
Footnotes

1. A PCA involving direct oblimin rotation produced a three-factor solution strikingly similar to the one resulting from the PCA with varimax rotation. In this analysis, factor 1 was associated with both factor $2(r=-.41)$ and factor $3(r=-.54)$.Factor 2 was associated with factor $3(r=.46)$. 
Table 1

Pearson product-moment correlations

\begin{tabular}{|c|c|c|c|c|c|c|c|c|}
\hline & CES & CES: 1 & CES: 2 & CES: 3 & PTSD & $\mathrm{BDI}$ & RSS & DES \\
\hline CES: Total Score & -- & $.63 * * *$ & $.56 * * *$ & $.54 * * *$ & $.69 * * *$ & $.47 * * *$ & $-.45 * * *$ & $.49 * * *$ \\
\hline CES: Factor 1 & & -- & .00 & .00 & $.34 * *$ & $.29 * *$ & $-.32 * *$ & $.29 * *$ \\
\hline CES: Factor 2 & & & -- & .00 & $.25^{*}$ & $.18^{ \pm}$ & $-.25^{*}$ & .07 \\
\hline CES: Factor 3 & & & & -- & $.63 * * *$ & $.30 * *$ & $-.20 *$ & $.48 * * *$ \\
\hline PTSD & & & & & -- & $.64 * * *$ & $-.47 * * *$ & $.71 * * *$ \\
\hline BDI & & & & & & -- & $-.71 * * *$ & $.54 * * *$ \\
\hline RSS & & & & & & & -- & $-.47 * * *$ \\
\hline DES & & & & & & & & -- \\
\hline
\end{tabular}

Note. $\mathrm{CES}=$ Centrality of Events; BDI $=$ Beck Depression Inventory; DES $=$ Dissociative Experiences Scale; PTSD = Posttraumatic stress disorder; RSI = Rosenberg Self-esteem Inventory

${ }^{ \pm} p<.1, * p<.05, * * p<.01, p<.001$ 
Table 2

Linear Regression Estimating Posttraumatic Stress Disorder Symptom Severity

\begin{tabular}{lcccc}
\hline & $\mathrm{B}$ & $\mathrm{SE}$ & $\mathrm{B}$ & $\mathrm{sr}^{2}$ \\
\hline Age & -.05 & .09 & -.04 & $<.01$ \\
WAIS-R Intelligence & -.03 & .07 & -.03 & $<.01$ \\
Dissociative Experiences Scale & $.33 * * *$ & .08 & .35 & .06 \\
Rosenberg Self-esteem & .38 & .21 & .15 & .02 \\
Depression severity & $.51 * * *$ & .13 & .36 & .08 \\
Centrality of Events & & & & .12 \\
\end{tabular}

Note. WAIS-R = Wechsler Adult Intelligence Scale - Revised;

$F(6,85)=34.74, p<.001, R^{2}=.71$

${ }^{ \pm} p<.1, * * * p<.001$ 
Table 3

Factor Loadings from Principal Component Analysis

\section{Factor Factor Factor}

\begin{tabular}{llrl} 
& 1 & 2 & 3 \\
\hline 8. This event tells a lot about who I am. & .72 & .19 & .10
\end{tabular}

2. I automatically see connections and similarities between this event and experiences in my present life.

$\begin{array}{lll}.70 & .15 & .35\end{array}$

7. I believe that people who haven't experienced this type of event think differently than I do.

$\begin{array}{lll}.69 & .34 \quad .04\end{array}$

11. I believe that people who haven't experienced this type of event, have a different way of looking upon themselves than I have.

9. I often see connections and similarities between this event and my current relationships with other people.

$\begin{array}{lll}.66 & .08 & .42\end{array}$

6. This event has become a reference point for the way I understand myself and the world.

$\begin{array}{lll}.55 & .40 & .24\end{array}$

4. This event can be seen as a symbol or mark of important themes in my life.

$\begin{array}{lll}.52 & .37 & .21\end{array}$

14. If I were to weave a carpet of my life, this event would be in the middle with threads going out to many other experiences.

$.47 \quad .37 \quad .36$

18. This event was a turning point in my life.

$\begin{array}{lll}.13 & .77 \quad .35\end{array}$

19. If this event had not happened to me, I would be a different person today. 
16. This event permanently changed my life.

5. This event is making my life different from the life of most other

$.39 \quad .66 \quad .15$

people.

3. I feel that this event has become part of my identity.

.50

$.65 \quad .21$

10. I feel that this event has become a central part of my life story.

20. When I reflect upon my future, I often think back to this event.

.15

.25

.88

17. I often think about the effects this event will have on my future.

.16

.32

.80

15. My life story can be divided into two main chapters: one is

$\begin{array}{lll}.13 & .42 & .66\end{array}$

before and one is after this event happened.

12. This event has colored the way I think and feel about other experiences.

1. This event has become a reference point for the way I understand new experiences.

13. This event has become a reference point for the way I look upon my future. 